South African Journal of Geomatics, Vol. 7. No. 3, November 2018

\title{
Estimating potential future (2030 and 2040) land use in the Bonsa catchment, Ghana, West Africa
}

\author{
Michael S. Aduah ${ }^{1 *}$, M. L. Toucher ${ }^{4}$, G. P. W. Jewitt ${ }^{2,3}$ \\ ${ }^{1}$ Department of Geomatics Engineering, University of Mines and Technology, PO Box 237, \\ Tarkwa, Ghana, msaduah@umat.edu.gh, soakodan@yahoo.com \\ ${ }^{2}$ Centre for Water Resources Research, University of KwaZulu-Natal, PBAG x01, Scottsville 3209, \\ Pietermaritzburg, South Africa \\ ${ }^{3}$ School of Engineering, University of KwaZulu-Natal, PBAG x01, Scottsville 3209, Durban, South \\ Africa \\ ${ }^{4}$ South African Environmental Observation Network, Grasslands-Wetlands-Forests Node, PO Box \\ 13053, Cascades, 3202, Pietermaritzburg, South Africa
}

DOI: $\underline{\text { htp: }: / d x . d o i . o r g / 10.4314 / s a j g . v 7 i 3.6 ~}$

\begin{abstract}
This study combined logistic regression, Markov chain and the Dyna-CLUE models to simulate land use patterns in the Bonsa catchment of Ghana, West Africa. Historical model validation produced Relative Operating Characteristics (ROC) statistics above 0.69; indicating a significant relationship between the driving factors and the land cover types, and overall accuracy of $71 \%$ as well as a Kappa statistic of 55\%, indicating a moderate agreement between observed and simulated land uses. The statistics of the historical model were used to simulate three plausible future land use scenarios. The historical simulation revealed that increases in population density, proximity to roads and expansion of mines were the major drivers that significantly increased the probability of settlement expansion and deforestation. Simulations of future land use showed that settlement expansion and deforestation may increase by similar margins for all scenarios, but the increase in secondary forests may be higher for the economic growth and reforestation (EGR) scenario, compared to the economic growth (EG) and the business-as-usual (BAU) scenarios. The mining areas may double in the future for all the scenarios, but shrubs/farms may increase in the BAU scenario, but reduce marginally in the EG and the EGR scenarios. The results of this study can be used to support land use planning and evaluation of the impacts of different future development pathways.
\end{abstract}

Keywords: Bonsa catchment, deforestation, driving factors, Dyna-CLUE, land use, logistic regression, West Africa

\section{Introduction}

Land cover/land use patterns over a period of time are determined by demographic, economic and environmental driving factors (Verburg et al., 1999; Castella et al., 2007) both at a national and global scale. An understanding of the patterns and the processes of land cover/land use changes is 
vital for effective land use planning (Dietzel and Clarke, 2006) and sustainable natural resources management (Castella et al., 2007). In Sub-Saharan African countries, such as Ghana, the majority of economic activities are centred on the exploitation of natural resources, which has resulted in rapid degradation of the natural environment over the past several decades. For example, the Gross Domestic Product (GDP) of Ghana increased from \$8 billion in 1984 to \$32 in 2010 (Kwakye, 2012). The increase in GDP has mainly resulted from growth in mining, oil and the agriculture sectors, including cocoa, tuber and fruit production, which have caused substantial land cover changes.

Although several land use mapping (Braimoh and Vlek, 2004; Attua and Fisher, 2010; FAO, 2010; Laurin et al., 2013; Aduah et al., 2015) and a few land use modelling studies (Mertens and Lambin, 2000; Braimoh and Vlek, 2005; Houessou et al., 2013) have been conducted in West Africa; in Ghana there is still a considerable knowledge gap on land use change processes, patterns and their driving forces at the local scale. In Ghana, only one study (Braimoh and Vlek, 2005) has attempted a quantitative explanation of the land use change processes in relation to their driving forces for the northern savannah ecological zones. To the best of our knowledge, there is a lack of deeper understanding of the land use change processes in the rainforest regions of Ghana. Studies in rainforest regions of Ghana have mainly quantified the land use changes (Attua and Fisher, 2010; Schueler et al., 2011; Aduah et al., 2015), none attempted to gain a quantitative and deeper understanding of the processes of changes in relation to their driving forces. Several case studies worldwide (Verburg and Veldkamp, 2004; Verburg and Overmars, 2009), show that there is a potential for a deeper understanding of the land use change processes in relation to their driving forces at the local scale, through spatially distributed land use modelling.

Land cover/use models provide a means to generate multi-temporal land cover maps from which the dynamism in land cover can be ascertained. During the past three decades, models have been used to establish quantitative relationships between land cover changes and their driving factors, in order to generate an understanding of the change processes and to simulate dynamic land cover/land use (Verburg et al., 1999; Hu and Lo, 2007), which can be used for the assessment of impacts of either future changes or impacts of different scenarios of changes (Robinson et al., 1994; Dietzel and Clarke, 2006). Land use models also contribute to effective planning by allowing the evaluation of different development scenarios (Dietzel and Clarke, 2006). This is especially important for data scarce regions, such as West Africa, where there is limited satellite images and aerial photographs, to derive land cover maps at regular time intervals.

Land cover models can be classified as stochastic or deterministic (Park et al., 2011b). The stochastic models include Markov Chains (MC), logistic regression (LR) and Cellular Automata (CA), while the deterministic models include Agent Based Models (ABM) (Dietzel and Clarke, 2006; Le et al., 2012) and models based on Geographical Information Systems (GIS). Though stochastic models incorporate biophysical, demographic and economic driving factors to simulate land use changes, they have difficulty in incorporating agents (Arsanjani et al., 2013). Agents include factors that are based on human decisions and activities. Purely statistical models also have 
a limitation in terms of dynamic modelling of the competition between different land uses (Dietzel and Clarke, 2006). The Dynamic Conversion of Land Use and its Effects (Dyna-CLUE) model, however, combines features of both deterministic and stochastic modelling, as well as estimation of land use demands, based on a Markov chain or any other appropriate technique (Verburg and Veldkamp, 2004; Verburg and Overmars, 2009; Park et al., 2011a; Hu et al., 2013).

This study aims to extend the knowledge on spatial patterns of land use changes in relation to their driving forces in West Africa, by conducting an empirical spatially distributed land use modelling, using the Bonsa catchment in southern Ghana as a study site and it builds on a previous land use change analysis study by Aduah et al. (2015). The main objective of the study to determine the significant driving forces of land use changes and to simulate potential land use maps for the Bonsa catchment. The data generated can be used to gain a deeper insight into land use change processes, as well as guide effective land use planning and enables assessment of the impacts of land use changes on the environment.

\section{Methods and Data}

\subsection{Description of Study Area}

The Bonsa catchment, a sub-catchment of the Ankobra River basin in Ghana, West Africa (Figure 1), is located between longitudes $1^{\circ} 41^{\prime}$ and $2^{\circ} 13^{\prime}$ West and latitudes $5^{\circ} 4^{\prime}$ and $5^{\circ} 43^{\prime}$ North. The catchment straddles the intersection of four districts, namely: Twifo-Heman Lower Denkyira to the north, Tarkwa Nsuaem and the Prestea-Huni Valley to the west and Mpohor Wassa East to the east. The catchment has a generally low relief, with the elevations ranging between 30 and $340 \mathrm{~m}$ above mean sea level and it drains an area of $1482 \mathrm{~km}^{2}$. The rainfall regime is bimodal and ranges between $1578 \mathrm{~mm}$ and $1982 \mathrm{~mm}$ per annum and the annual average minimum and maximum temperatures are $22^{\circ} \mathrm{C}$ and $32^{\circ} \mathrm{C}$, respectively. Predominant land cover consists of evergreen and secondary forests, with scattered shrubs and farms. During the past 26 years, (i.e between 1986 and 2011), deforestation rates have been increasing: 0.33\% between 1986 and 1991, 0.70\% between 1991 and 2002 and 2\% between 2002 and 2011 (Aduah et al., 2015). Major economic activities in the catchment include open-pit gold mining, rubber cultivation and smallscale cocoa and food crop production. 




Figure 1: Map of the Bonsa catchment of the Ankobra basin, Ghana

\subsection{Model Details}

\subsubsection{Dyna-CLUE Model}

The dynamic Conversion of Land Use and its Effects modelling frame work (Dyna-CLUE), was developed by the Institute of Environment at the University of Wageningen, Netherlands, to simulate land use change (Verburg and Veldkamp, 2004). The model uses empirical relations between land use, its driving factors, as well as dynamic modelling of the competition between land use types. Dyna-CLUE has two modules, (i) the non-spatial and (ii) the spatial allocation module. The non-spatial module calculates predicted land use change areas (demand) for each land use type, while the spatial module allocates the predicted (demand) land use areas spatially in the study region. Land use demand is the area per land use type and it is associated with both potential and actual land use. The land use demand was predicted outside of the Dyna-CLUE model based on historical land use changes obtained from Aduah et al. (2015) as well as a Markov chain model (Robinson et al., 1994; Hu et al., 2013) shown in equation 1.

$$
X_{n}=X_{(n-1)} P
$$

Where $X_{n}$ is the computed land use demand, $\mathrm{X}_{(n-1)}$ is the initial land use demand (the land use map of 2002) and $P$ is the annual land use transition probability matrix, derived from the land use transition probability. 
The land use transition probability between the selected initial year (2002) and the final year (2011), obtained from a companion paper (Aduah et al., 2015) were used in Takada's software (Takada et al., 2010) to compute the annual land use transition probability matrix (Table 1).

Table 1: Annual transition probability matrix (2002 to 2011)

\begin{tabular}{|c|c|c|c|c|c|c|c|}
\hline & \multicolumn{7}{|c|}{ From 2002} \\
\hline & Land cover & $\begin{array}{r}\text { Secondary } \\
\text { forest }\end{array}$ & Water & $\begin{array}{r}\text { Evergreen } \\
\text { forest }\end{array}$ & Settlements & Shrubs/farms & $\begin{array}{r}\text { Mining } \\
\text { areas }\end{array}$ \\
\hline \multirow{6}{*}{ To 2011} & Secondary forest & 0.86 & 0 & 0.01 & 0 & 0.06 & 0 \\
\hline & Water & 0 & 0.83 & 0 & 0 & 0 & 0.01 \\
\hline & Evergreen forest & 0.03 & 0.03 & 0.98 & 0.01 & 0.02 & 0.01 \\
\hline & Settlements & 0 & 0 & 0 & 0.96 & 0.01 & 0.01 \\
\hline & Shrubs/farms & 0.11 & 0 & 0.01 & 0.03 & 0.89 & 0.02 \\
\hline & Mining areas & 0 & 0.16 & 0 & 0 & 0.01 & 0.94 \\
\hline
\end{tabular}

The spatial allocation module in Dyna-CLUE uses the output of the non-spatial module (i.e. area predicted in equation 1), spatial/area policy restrictions, land use conversion sequence matrices and land use location suitability to predict the new location of land use types. Spatial policy restrictions are used to prevent land use changes in selected areas of importance such as nature reserves or protected areas, while land use conversion sequence matrices indicate land use transition sequences (Verburg and Veldkamp, 2004), but land use location suitability indicates the probability of occurrence of each land use class within a study area. In this study two spatial restriction maps were used- i.e. one that allowed land cover changes within the whole study area and another, which allowed land cover conversions to urban and mining areas in selected parts of the study area. For mining areas, the spatial restriction map was extracted from lease and prospecting license boundaries (Aduah et al., 2015), while for the settlements, the map was based on historical land cover trends. The conversion sequence matrix (Table 2) in this study was derived by inspecting the land use/cover change matrix between 2002 and 2011. In Table 2, 1 indicates that transition is allowed, while 0 indicates that transition is not allowed. For the location suitability, maps of individual land use classes, as well as the land use change driving factors (population density, distance from centre of town, distance from roads, distance from Tarkwa, elevation, distance from rivers, slope, aspect, distance from outskirts of town, distance to mining concessions etc) were converted to ASCII files and imported to IBM SPSS statistical software to perform binary logistic regression. The suitability/probability of each land use class given the driving factors was computed according to equation [2].

$$
\log \left(\frac{p_{i}}{1-P_{i}}\right)=\beta_{0}+\beta_{1} X_{1}+\beta_{2} X_{2}+\cdots+\beta_{n} X_{n}
$$

Where $P_{i}$ is the probability of occurrence of a land use class in location $\mathrm{i}, X$ is the location factor and $\beta$ is the logistic regression coefficient and $1,2 \ldots n$ is the number of coefficients/factors

The Dyna-CLUE model also uses land use conversion elasticity, which controls the reversibility of land cover changes (Verburg and Veldkamp, 2004) and it ranges from 0 for land cover types, 
which are easily changed (e.g. shrubs to urban), to 1 for those that are not easily changed (e.g. urban to forest). The binary logistic regression coefficients and the other variables calculated above were input in the Dyna-CLUE model, to simulate land cover/land use. Figure 2 shows how the inputs of the Dyna-CLUE model were organised to simulate land use/cover maps.

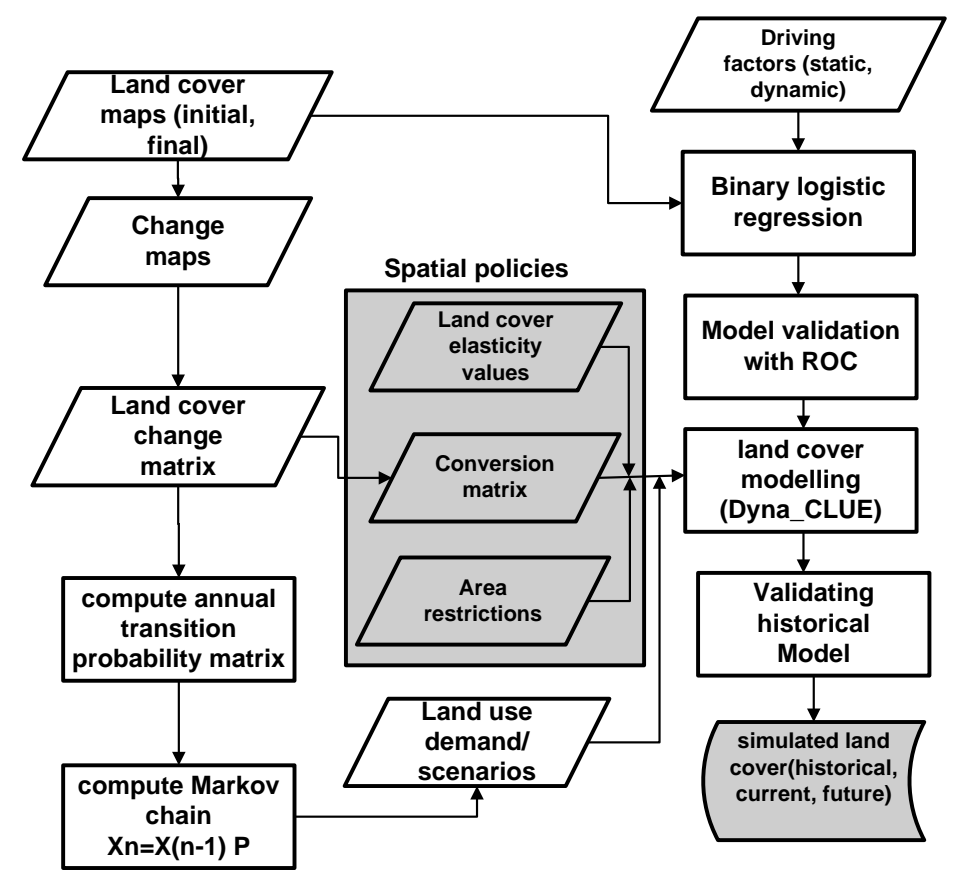

Figure 2: Land use/land cover modelling procedure

Table 2: Conversion matrix for 2002 to 2011 land use simulations

\begin{tabular}{|c|c|c|c|c|c|c|c|}
\hline & \multicolumn{7}{|c|}{ From 2002} \\
\hline & Land cover & $\begin{array}{r}\text { Secondary } \\
\text { forest }\end{array}$ & Water & $\begin{array}{r}\text { Evergreen } \\
\text { forest }\end{array}$ & Settlements & Shrubs/farms & Mining areas \\
\hline \multirow{6}{*}{ To 2011} & Secondary forest & 1 & 0 & 1 & 0 & 0 & 0 \\
\hline & Water & 0 & 1 & 0 & 0 & 0 & 0 \\
\hline & Evergreen forest & 0 & 0 & 1 & 0 & 0 & 0 \\
\hline & Settlements & 0 & 0 & 0 & 1 & 1 & 0 \\
\hline & Shrubs/farms & 1 & 0 & 0 & 0 & 1 & 0 \\
\hline & Mining areas & 0 & 0 & 0 & 0 & 0 & 1 \\
\hline
\end{tabular}

\subsubsection{Model Validation and Future Land Use Scenarios}

The model validation was performed using two metrics; namely the relative operating characteristics (ROC) statistics (Verburg and Veldkamp, 2004) of the logistic regression to test the validity of the relationship between the land use types and the driving factors and the Kappa statistic (Arsanjani et al., 2013), as well as the overall accuracy of the simulated map. After validating the Dyna-CLUE model for the historical land use simulation, three future scenarios/demands of land use changes were created to simulate potential land use in the Bonsa catchment. The land use scenarios were: i) the business-as-usual (BAU) scenario, where the current economic and environmental objectives persist, ii) the economic growth scenario (EG), where economic 
development is assumed to be promoted through expansion in mining operations, as well as increased rubber production and (iii) the economic growth and reforestation (EGR), which is similar to the EG, but prescribes higher rates of forest rehabilitation into the future.

\section{Results}

\subsection{Model Validation and Simulated Land Use Maps}

The logistic regression results are shown in Table 3 for the eleven independent driving factors and the six land cover classes in the Bonsa catchment. The ROC statistics ranged from 0.69 for the secondary forest to 0.98 for the settlements and mining areas. The regression coefficients, as well as the constants, were significant at the $95 \%$ confidence level, indicating that the logistic regression model is capable of predicting the probability of occurrence of the land covers in the catchment. The positive coefficients show that the probability of observing the land covers increase for the independent factors, while the negative coefficients show the opposite. Table 3 shows that with increasing population density, the probability of occurrence of secondary forest and evergreen forest; reduces, while the probability increases for settlements and shrubs/farms. This indicates that population growth contributes to deforestation, as a result of increasing area of shrubs/farms and settlements in the catchment.

Table 3: Binary logistic regression statistics of 2011 land cover and driving factors

\begin{tabular}{lrrrrrr}
\hline Factor & Secondary forest & Water & Evergreen forest & Settlements & Shrubs/farms & Mining areas \\
\cline { 2 - 6 } & Coefficient* & Coefficient* & Coefficient* & Coefficient* & Coefficient* & Coefficient* \\
\hline 2002 population density & -0.0060 & & -0.0191 & 0.0078 & 0.0051 & \\
Distance from centre of towns & 0.0002 & & -0.0001 & -0.0009 & -0.00001 & -0.0004 \\
Distance from roads & -0.0003 & & 0.0005 & -0.0019 & -0.0003 & \\
Distance from Tarkwa & -0.00001 & & -0.0001 & 0.00004 & 0.00003 \\
Elevation & 0.0018 & 0.0263 & 0.0013 & -0.0110 & -0.0009 & 0.0161 \\
Distance from rivers & 0.0001 & & 0.0001 & 0.00002 & -0.0001 & \\
Aspect & & & 0.0001 & -0.0007 & & -0.0002 \\
Distance from outskirts of towns & -0.00001 & & 0.0001 & -0.0032 & 0.00002 & \\
Easting coordinates & -0.0001 & & 0.00002 & 0.00001 & -0.0001 & -0.0020 \\
Northing coordinates & 0.00003 & & 0.00003 & & & -0.2289 \\
Distance from mining concessions & & -0.0014 & & & & \\
constant & 14.0627 & -5.4279 & -29.0138 & -5.5325 & 21.2753 & \\
ROC statistic & 0.6908 & 0.9746 & 0.8247 & 0.9844 & 0.7881 & \\
\hline *all coefficients significant at $\mathrm{p}<0.05$ & & & & & &
\end{tabular}

Furthermore, the probability of observing settlements and shrubs/farms increases with proximity to centre of towns, roads and outskirts of towns, but increasing elevation has the opposite effect. Additionally, the logistic regression model shows that for mining and water (mainly mining tailings dams), the probability of their occurrence increased with elevation, but decreased with distance from mining concessions.

Validation of the historical model indicated that the simulation corresponded well with the historical land use, resulting in an overall accuracy of 71\% and a Kappa statistic of 55\% (Table 4), after comparing the observed and the simulated land use map of 2011(Figure 3). According to 
Landis and Koch (1977), a Kappa of 55\% demonstrates that the model's predictive power is moderate. The moderate performance of the model in the Bonsa catchment can be attributed to inadequate data and lack of information on land use decisions of individuals and organisations. Generally, information on the land use plans in the catchment was not available, although this type of information is necessary for projecting changes in the land cover/land use (Verburg and Veldkamp, 2004). Furthermore, the land use maps of 2002 and 2011 also introduced uncertainties into the modelling. This is because the discrimination between secondary forest and shrubs/farms was poor; although the overall mapping accuracies of the land use maps were acceptable (Aduah $e t$ al., 2015). Therefore the potential future land use maps used for analysis in this study was limited to the near future $(2030,2040)$ time slice only, as the uncertainties in simulation increases with time. Figure 3 and 4 show the results of future land use projections. The figures show that the settlement areas in the scenarios increased by almost the same margin, while secondary forests decreased in the BAU scenario, it increased in the EG and the EGR scenarios, with higher increases in the EGR than the EG.

Table 4: Error Matrix for observed and simulated 2011 land cover map

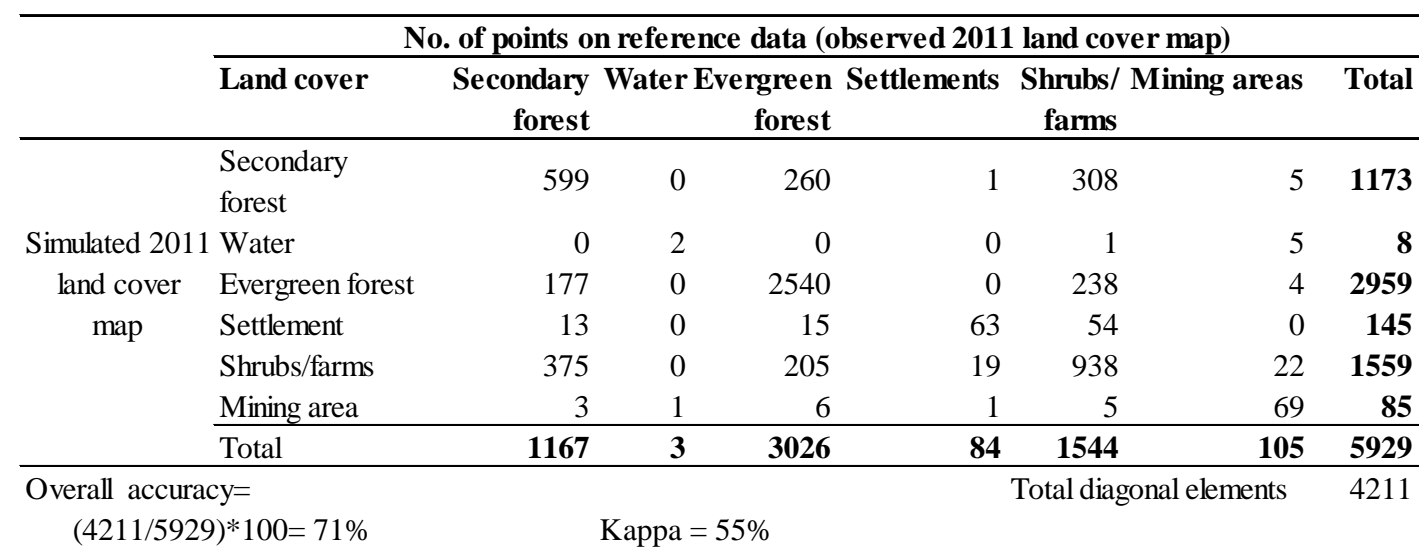





Figure 3: Observed (a) and simulated (b) land cover maps for 2011 and (c) predicted land cover maps for 2030 and 2040 


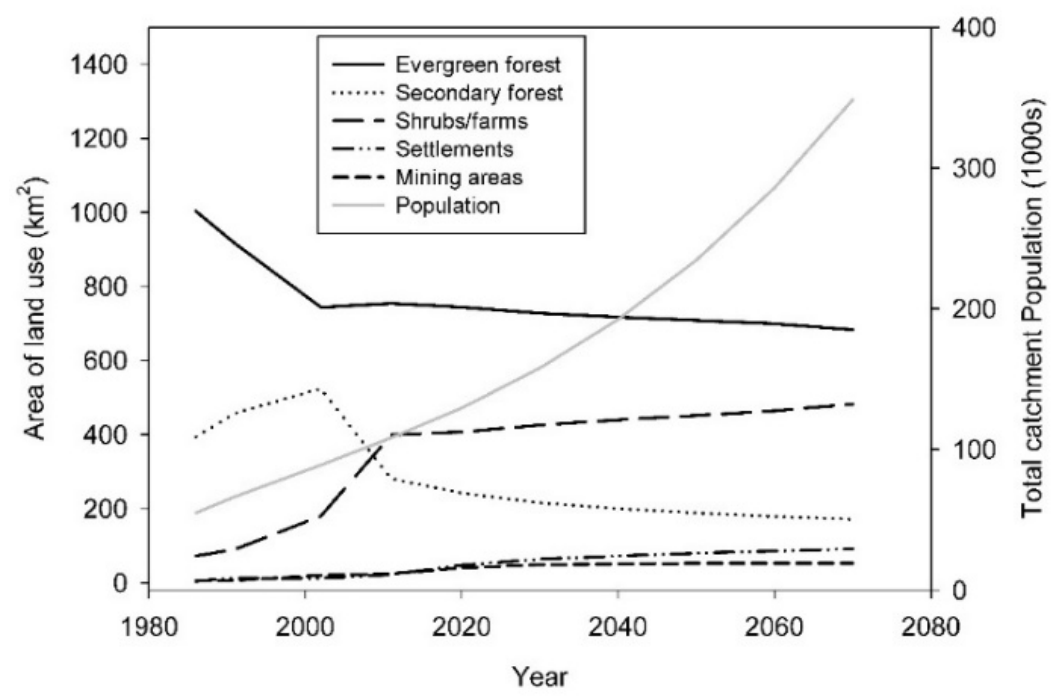

Figure 4: Total projected population of Bonsa catchment (1986 to 2070), land cover areas from 1986 to 2011 (observed) and simulated land cover areas from 2020 to 2070 for the BAU scenario

\section{Discussion}

This study has demonstrated a moderately successful modelling of land cover/use changes for both historical and future scenarios, using a combination of logistic regression, Markov chain and the Dyna-CLUE models. Logistic regression modelling was able to identify eleven driving factors (Table 3) in the Bonsa catchment which significantly influences occurrence of the land use types, while the Dyna-CLUE model successfully allocated the land use types spatially by modelling the dynamic competition between the different land use types. The dynamic competition was controlled by the statistics of the regression model, the demand, the change matrix (transition sequences) and the elasticity of the land cover (Verburg and Overmars, 2009). As a result of data scarcity and poor accuracy of the available data, comparison of simulated and observed land cover of 2011 resulted in only a moderate overall accuracy of $71 \%$ and a Kappa of 55\%. However, there is confidence in the model for projecting near future land uses as the logistic regression coefficients involving the driving factors and land uses is significant at the 95\% confidence level and since the overall trend (Figure 3) in land cover changes is well simulated. Also since the purpose of the modelling was to provide plausible pathways of land cover changes under several scenarios, the modelling approach is consistent with previous studies (Park et al., 2011a).

For the future scenarios of land cover changes (BAU,EG, EGR), the study reveals that in the future, there may be extensive land cover/land use changes in Bonsa catchment (Figure 3 and 4), through population growth and increased surface mining activities(Aduah et al., 2015). The simulated increase in mining areas is not surprising because several mining leases and prospecting licenses have been granted for mining to start in the near future (Aduah et al., 2015). The historical (Aduah et al., 2015) and predicted land uses (2030 and 2040) indicates that the Sahel Syndrome (Petschel-Held et al., 1999) may exist in the southern part of Ghana, as the increasing poor population of Bonsa catchment, who have no other livelihoods, convert forested lands into agriculture, thereby contributing significantly to degradation of the environment. With regards to 
influence of population size on deforestation, results of this study are similar to those for the Eastern province of Cameroon (Mertens and Lambin, 2000) and the West Biosphere reserve in Northern Benin (Houessou et al., 2013), but contradict that of Braimoh and Vlek (2005), where population did not contribute significantly to deforestation in the northern Savannah of Ghana. However, accessibility factors had significant influence on deforestation, similar to the results of previous studies in West Africa (Braimoh and Vlek, 2005; Houessou et al., 2013).

It is important to state that the maps generated under the land use scenarios in this study do not represent real land uses. The maps are only a projection of different development pathways for the catchment and are intended to be used to support the formulation/revision and evaluation of land use policies. Simulating land use is important in providing data to gain a deeper understanding of the land use change process, as well as for effective land use planning and natural resources management. It appears that the plethora of economic, environmental, health, social and health problems facing West African countries is largely the result poor land use planning, as the causes of these problems are linked to land use decisions at the local scale. Settlement expansion as urban sprawl, for example, does not only lead to potential pollution of surface and ground water through nonpoint source pollution and increases in carbon emissions with removal of vegetation and burning of fossil fuels (Randolph, 2012), it also makes it challenging to provide social services and amenities to citizens as the urban area increases at a rate faster than the planning and execution of development by government authorities. Hence, adoption of consistent evaluation and simulation techniques will provide planners in West Africa with the requisite information to assess different development scenarios, which account for important variables such as population growth and changes in per capita incomes, far into the future, and so control land use changes and plan development sustainably. The methodology adopted in this study was consistent and considered reasonable, as it ensured that multiple land use classes were simulated spatially, based on biophysical and socio-economic drivers. The adopted methodology also ensured that simultaneous removal and regeneration of vegetation at different parts of a catchment, which occurs in reality, was taken into account.

Although as the period of simulation exceeds ten years, the credibility of land use projections starts to reduce with time (Robinson et al., 1994). The long-term projections of land use, which were made in this study are necessary because they lead to understanding of any feedbacks beyond the historically observed land use change process. Long-term simulations of land use also produce long-term data, consistent with GCM climate projection time scales, which are required for assessment of Global Change impacts far into the future. Furthermore, regardless of the deficiencies, projections of land use using consistent techniques as demonstrated in the study, is superior to ad hoc predictions using expert judgement or the use of assumed land use scenarios. This study has emphasised the importance of adequate information on drivers of land use changes to successful simulation, as the lack of adequate data in the Bonsa catchment resulted in only a moderately successful simulation. However, the use of multiple land use scenarios (BAU, EG and 
EGR) is a way to quantify the uncertainties associated with relying on a single scenario and use of inadequate as well as poor data, thereby enhancing the applicability of simulation results.

\section{Conclusion}

The study has demonstrated a successful combination of logistic regression, Markov chain and the Dyna-CLUE models to simulate land cover/land use in the Bonsa catchment, Ghana, West Africa. The study has identified eleven driving factors, which significantly influence land cover changes in the Bonsa catchment and has generated land cover maps for both the historical, as well as future time slices. The results of the study reveal that increases in population density, proximity to roads and increase in surface mining activities are the major drivers of deforestation and settlement expansion in the catchment. It is therefore suggested that in order to promote sustainable development, land use planning in the Bonsa catchment should not be for the urban areas alone, as is the case in many districts in Ghana, but for the entire catchment and should incorporate protection of forests and promotion of sustainable mining operations. Although the accuracy of the simulation for the 2011 land cover was only moderate, spatially explicit and dynamic simulation of multiple land cover changes is a far more realistic way to generate potential future land use data than the use of extreme assumptions of land changes. The dynamic land use simulation accounts for both biophysical and socio-economic driving forces, as well as enforcement of known trends of land cover changes within the study area in a spatially explicit manner. Therefore the maps and statistics generated in this study can be used to support land use planning, as well as assess the impacts of potential future land cover changes on the environment.

\section{References}

Aduah, MS, Warburton, ML and Jewitt, G. 2015. Analysis of land cover changes in the Bonsa catchment, Ankobra Basin, Ghana. Applied Ecology and Environmental Research 13(4):935-955.

Arsanjani, JJ, Helbich, M, Kainz, W and Boloorani, AD. 2013. Integration of logistic regression, Markov chain and cellular automata models to simulate urban expansion. International Journal of Applied Earth Observation and Geoinformation 21265-275.

Attua, EM and Fisher, JB. 2010. Historical and Future Land-Cover Change in a Municipality of Ghana. Earth Interactions 15(9):1-26.

Braimoh, AK and Vlek, PLG. 2004. Land-Cover Change Analyses in the Volta Basin of Ghana. Earth Interactions 8(21):1-17.

Braimoh, AK and Vlek, PLG. 2005. Land-cover change trajectories in Northern Ghana. Environmental Management 36(3):356-373.

Castella, J-C, Pheng Kam, S, Dinh Quang, D, Verburg, PH and Thai Hoanh, C. 2007. Combining top-down and bottom-up modelling approaches of land use/cover change to support public policies: Application to sustainable management of natural resources in northern Vietnam. Land Use Policy 24(3):531-545.

Dietzel, C and Clarke, K. 2006. The effect of disaggregating land use categories in cellular automata during model calibration and forecasting. Computers Environment and Urban Systems 30(1):78-101.

FAO. 2010. Global Forest Resources Assessment 2010, Country Report, Ghana. In: Affum-Baffoe, K (ed.). Food and Agricultural Organisation (FAO), Rome, Italy. 
Houessou, LG, Teka, O, Imorou, IT, Lykke, AM and Sinsin, B. 2013. Land Use and Land-Cover Change at "W" Biosphere Reserve and Its Surroundings Areas in Benin Republic (West Africa). Environment and Natural Resources Research 3(2):87-101.

Hu, Y, Zheng, Y and Zheng, X. 2013. Simulation of land-use scenarios for Beijing using CLUE-S and Markov composite models. Chinese Geographical Science 23(1):92-100.

$\mathrm{Hu}, \mathrm{ZY}$ and Lo, CP. 2007. Modeling urban growth in Atlanta using logistic regression. Computers Environment and Urban Systems 31(6):667-688.

Landis, JR and Koch, GG. 1977. The measurement of observer agreement for categorical data. Biometrics 33(1):159-174.

Laurin, GV, Liesenberg, V, Chen, Q, Guerriero, L, Del Frate, F, Bartolini, A, Coomes, D, Wilebore, B, Lindsell, J and Valentini, R. 2013. Optical and SAR sensor synergies for forest and land cover mapping in a tropical site in West Africa. International Journal of Applied Earth Observation and Geoinformation 21(2013):7-16.

Le, QB, Seidl, R and Scholz, RW. 2012. Feedback loops and types of adaptation in the modelling of land-use decisions in an agent-based simulation. Environmental Modelling \& Software 27-28(2012):83-96.

Mertens, B and Lambin, EF. 2000. Land-cover-change trajectories in southern Cameroon. Annals of the Association of American Geographers 90(3):467-494.

Park, JY, Park, MJ, Joh, HK, Shin, HJ, Kwon, HJ, Srinivasan, R and Kim, SJ. 2011a. Assessment of MIROC3.2 HIRES climate and CLUE-S land use change impacts on watershed hydrology using SWAT. Transactions of the Asabe 54(5):1713-1724.

Park, S, Jeon, S, Kim, S and Choi, C. 2011b. Prediction and comparison of urban growth by land suitability index mapping using GIS and RS in South Korea. Landscape and Urban Planning 99(2):104-114.

Petschel-Held, G, Block, A, Cassel-Gintz, M, Kropp, J, Lüdeke, MKB, Moldenhauer, O, Reusswig, F and Schellnhuber, HJ. 1999. Syndromes of Global Change: a qualitative modelling approach to assist global environmental management. Environmental Modeling \& Assessment 4(4):295-314.

Randolph, J. 2012. Environmental Land Use Planning and Management, Island Press, Washington, USA.

Robinson, J, Brush, S, Douglas, I, Gradel, TE, Graetz, D, Hodge, W, Liverman, D, Melillo, J, Moss, R, Naumov, A, Njiru, G, Penner, J, Rogers, P, Ruttan, J and Sturdevant, J. 1994. Land-Use and Land-Cover Projections: Report of Working Group C. In: Meyer, WB and Turner Ii, BL (eds.) Changes in Land Use and Land Cover: A Global Perspective. Cambridge University Press, Cambridge, United Kingdom.

Schueler, V, Kuemmerle, T and Schroeder, H. 2011. Impacts of Surface Gold Mining on Land Use Systems in Western Ghana. Ambio 40(5):528-539.

Takada, T, Miyamoto, A and Hasegawa, SF. 2010. Derivation of a yearly transition probability matrix for land-use dynamics and its applications. Landscape Ecology 25(2010):561-572.

Verburg, P and Veldkamp, A. 2004. Projecting land use transitions at forest fringes in the Philippines at two spatial scales. Landscape Ecology 19(1):77-98.

Verburg, PH, de Koning, GHJ, Kok, K, Veldkamp, A and Bouma, J. 1999. A spatial explicit allocation procedure for modelling the pattern of land use change based upon actual land use. Ecological Modelling 116(1):45-61.

Verburg, PH and Overmars, KP. 2009. Combining top-down and bottom-up dynamics in land use modeling: exploring the future of abandoned farmlands in Europe with the Dyna-CLUE model. Landscape Ecology 24(9):1167-1181. 